\title{
Human cytomegalovirus seroprevalence and titres in solid organ transplant recipients and transplant donors in Seoul, South Korea
}

Yeonju La, Da Eun Kwon, Seul Gi Yoo, Kyoung Hwa Lee, Sang Hoon Han [i] and Yong Goo Song

\begin{abstract}
Background: Human cytomegalovirus (HCMV) can cause poor outcomes in solid organ transplant (SOT) recipients; moreover, it is associated with cardiovascular diseases (CVD) in the general population. Accordingly, anti-HCMV immunoglobulin $\mathrm{G}(\mathrm{IgG})$ seroepidemiology may be useful in identifying the risk of post-SOT HCMV infection or disease as well as immunosenescence or CVD. However, HCMV seroprevalence and titre have not been fully evaluated with regard to age distribution or compared between SOT recipients and healthy individuals in South Korea.
\end{abstract}

Methods: We retrospectively retrieved all unduplicated anti-HCMV IgG results of individuals aged $>1$ year evaluated between July 2006 and November 2017 at Severance Hospital in Seoul. The cohort, excluding haematopoietic stem cell transplant recipients and subjects with equivocal values, included 2184 SOT recipients and 3015 healthy transplant donors. All IgG results in the SOT recipients were measured during the pre-transplant period.

Results: The overall $\operatorname{lgG}$ seroprevalence and titres were significantly higher among SOT recipients than among healthy donors ( $98.7 \%$ vs. $88.6 \%, p<0.001$, and $64.7 \pm 44.3$ vs. $49.8 \pm 20.6$ arbitrary units $/ \mathrm{mL}, p<0.001$, respectively). The lowest seropositive rate in the SOT group was observed in recipients aged between 11 and 15 years (70.6\%). The frequency of seropositivity among adults aged $\geq 41$ years increased to $\geq 90 \%$ in SOT recipients and healthy donors. Age was independently associated with higher HCMV seroprevalence (41-60 years, OR, 76.4, 95\% Cl, 24.5$238.9, p<0.001 ; \geq 61$ years, $\mathrm{OR}, 4.4,95 \% \mathrm{Cl}, 1.3-14.9, p<0.001$, compared to $\leq 40$ years). The healthy donor group had an independently low HCMV seropositive rate (OR, $0.1,95 \% \mathrm{Cl}, 0.1-0.2, p<0.001)$.

Conclusions: HCMV seropositivity was the lowest among school-aged children and adolescents. IgG testing revealed an intermediate serostatus risk of post-transplant HCMV infection and disease for most adult SOT recipients in South Korea.

Keywords: Age, Human cytomegalovirus, Seroprevalence, Solid organ transplantation

\footnotetext{
* Correspondence: shhan74@yuhs.ac

Department of Internal Medicine, Division of Infectious Disease, Yonsei

University College of Medicine, Seoul, Republic of Korea
}

(c) The Author(s). 2019 Open Access This article is distributed under the terms of the Creative Commons Attribution 4.0 International License (http://creativecommons.org/licenses/by/4.0/), which permits unrestricted use, distribution, and reproduction in any medium, provided you give appropriate credit to the original author(s) and the source, provide a link to the Creative Commons license, and indicate if changes were made. The Creative Commons Public Domain Dedication waiver (http://creativecommons.org/publicdomain/zero/1.0/) applies to the data made available in this article, unless otherwise stated. 


\section{Background}

The genomic DNA of human cytomegalovirus (HCMV) can be incorporated into the host chromosome after primary acquisition, usually in early life, and be retained in a latent form throughout life [1-4]. The complicated mechanisms involved in the latent-to-lytic switch can induce temporary or sustained HCMV replication, leading to active cytolytic inflammation $[1,3,4]$. In both immunocompetent and immunocompromised patients, reactivation of latent $\mathrm{HCMV}$ can result in direct tissue damage that causes end organ disease [1, 5-7]. In addition, the indirect immunomodulatory effects caused by the reactivated HCMV may produce detrimental outcomes, such as increased mortality and graft dysfunction or failure and rejection, in recipients of solid organ transplantation (SOT) $[8,9]$. Moreover, the persistent and excessive activation of the HCMV-specific cellmediated immune response and the consequent immune exhaustion or accelerated immunosenescence in the nonimmunocompromised population could predispose these individuals to chronic inflammatory diseases, such as cardiovascular diseases (CVDs), as well as aging [10-13].

The profound clinical influence of HCMV on personal and public health makes it reasonable to acquire detailed information regarding the number of individuals that have asymptomatic HCMV in a certain region [14]. Surveillance for HCMV seroprevalence, which is assessed using an anti-HCMV immunoglobulin G (IgG) test, may be epidemiologically important as a means of predicting various related chronic diseases, particularly in older subjects, as global societies age $[11,12,15]$. Additionally, the pre-transplant HCMV serostatus in donors and recipients is an important factor predicting post-transplant HCMV infection and disease; moreover, it provides information that would be useful in developing individually tailored anti-HCMV preventive strategies for SOT recipients $[1,3,9,16,17]$.

The anti-HCMV IgG positive rates vary widely by era, geographic distribution, age group, and population characteristics [18, 19]. In 2019, Zuhair et al. estimated the mean HCMV seroprevalence in the global general population to be $83 \%$ (95\% uncertainty interval, 78-88\%), ranging from $90 \%(85-94 \%)$ in the Eastern Mediterranean region to $66 \%(56-74 \%)$ in Europe, among the six regions demarcated by the World Health Organization (WHO) [14]. The national burden of HCMV also varies between $18 \%$ in Canada and $100 \%$ in Egypt, Iran, Thailand, and Turkey [14]. However, no report, to our knowledge, has evaluated HCMV seroepidemiology across all ages of a general population, among women of reproductive age, or among SOT recipients in South Korea, which has experienced rapid socioeconomic development and advances in public health in recent years $[14,20]$.
Therefore, this study aimed to evaluate the recent HCMV seroprevalence and anti-HCMV IgG titres among SOT recipients, particularly according to age distribution, in Seoul, South Korea.

\section{Methods \\ Study design and population}

For the retrospective cohort study, we retrieved all unduplicated anti-HCMV IgG results and IgG titres for tests performed between July 2006 and November 2017 from the electronic medical records of Severance Hospital, a university-affiliated tertiary care centre in Seoul, South Korea. Infants $(n=488)$ were excluded, because they could possess maternal anti-HCMV IgG for a year after birth [21]. After the further deletion of 34 equivocal results, we stratified the total cohort into two groups of 2184 SOT recipients and 3015 healthy transplant donors who underwent this screening for organ donation, irrespective of the implementation of donation surgery. The SOT recipients group included all recipients who received transplants from living or deceased donors. Our cohort did not include SOT recipients had received haematopoietic stem cell transplantation (HSCT) before and after SOT or re-transplantation or multiple-organ transplantation or human immunodeficiency virusinfected individuals. For all SOT recipients, anti-HCMV IgG values were evaluated during the pre-transplant period within 3 months of SOT. The ages at the time of testing, anti-HCMV IgG titres, and transplant organs were also recorded. Patient ages were grouped in 5-year intervals up to 40 years of age and, then, in 20-year intervals. The study was approved by the institution review board in Gangnam Severance Hospital, which waived the requirement for informed consent because of retrospective data collection without personally identifiable information (IRB approval No: 3-2018-0139).

\section{Measurement of anti-human cytomegalovirus IgG antibody}

Serum samples were automatically subjected to quantitative anti-HCMV IgG testing using an enzyme-linked fluorescent immunoassay (VIDAS ${ }^{\circ}$, bioMérieux Cop., Marcy-l'Etoile, Lyon, France). Antigens from the HCMV AD169 laboratory strain were used as the positive control. The antibody titre is expressed in arbitrary units $(\mathrm{aU}) / \mathrm{mL}$. Qualitatively, the results were reported as positive, equivocal, and negative if the titres were $\geq 6,4$ to $<$ 6 , and $<4 \mathrm{aU} / \mathrm{mL}$, respectively. The results of antiHCMV IgG tests in the analyses were categorised as positive or negative.

\section{Statistical analyses}

We used the independent two-sample t-test and the chisquare test or Fisher's exact test, respectively, to examine 
differences in continuous and nominal variables between SOT recipients and healthy transplant donors. The posthoc analyses in the nominal variables were performed by adjusted standardised residuals to control for type I error inflation (adjusted $p$ value). An analysis of variance (ANOVA) with the Bonferroni post-hoc test was used for multiple comparisons of IgG titres between transplant organs. Multivariate logistic regression analyses were performed to identify the independent effects of age groups and sex on HCMV seropositivity. Data are expressed as numbers (percentages) or means \pm standard deviations or odds ratio (OR) (95\% confidence intervals $[\mathrm{CI}]$ ). SAS version 9.3 (SAS Institute Inc., Cary, NC, USA) was used for the statistical analyses. A two-tailed $p$-value $\leq 0.05$ was considered statistically significant.

\section{Results}

\section{HCMV IgG results from SOT recipients and healthy} transplant donors

The overall anti-HCMV IgG positivity rate was $92.8 \%$ in the total of 5199 subjects. The HCMV seropositivity in males was not significantly different from that in females among SOT recipients $(99.8 \%[n=1354]$ vs. $98.4 \%[n=$ 830], $p=0.564)$. However, among healthy transplant donors, males had a significantly lower HCMV seropositive rate $(84.1 \%[n=1681]$ vs. $86.8 \%[n=1334], p=$ 0.039 ). The frequency of anti-HCMV IgG positivity in all ages was significantly higher among SOT recipients than among healthy transplant donors $(98.7 \%$ vs. $88.6 \%$, $p<0.001$ ) (Table 1).

\section{HCMV seroprevalence according to age groups}

There were few subjects aged $\leq 15$ years in the SOT recipients group $(44 / 2184,2.0 \%)$ and none in the group of 3015 healthy transplant donors. The proportion of antiHCMV IgG positive results was extremely high among SOT recipients aged $\geq 31$ years and among healthy transplant donors aged $\geq 61$ years. In contrast, HCMV seropositive rates were the lowest among those between 11 and 15 years of age in the SOT recipients group (70.6\%) and those between 16 and 20 years of age among the healthy transplant donors (54.8\%). The HCMV seropositivity in the healthy donors continuously increased with age from $54.8 \%$ in those aged between 16 and 20 years to $99.5 \%$ in those $\geq 61$ years of age (Table 1 ).

SOT recipients had significantly higher rates of seropositivity, compared to healthy transplant donors, among those between 16 to 20 (93.2\% vs. $54.8 \%, p<0.001), 21$ to

Table 1 HCMV IgG seroprevalence in solid organ transplant recipients and healthy transplant donors by age distribution

\begin{tabular}{|c|c|c|c|c|}
\hline Age (years) & Anti-HCMV lgG & SOT recipients $(n=2184)$ & Healthy transplant donors $(n=3015)$ & $p$-value \\
\hline \multirow[t]{2}{*}{$1-5$} & Positive & $12(80.0)$ & $0(0)$ & N/A \\
\hline & Negative & $3(20.0)$ & $0(0)$ & \\
\hline \multirow[t]{2}{*}{$6-10$} & Positive & $9(75.0)$ & $0(0)$ & N/A \\
\hline & Negative & $3(25.0)$ & $0(0)$ & \\
\hline \multirow[t]{2}{*}{$11-15$} & Positive & $12(70.6)$ & $0(0)$ & N/A \\
\hline & Negative & $5(29.4)$ & $0(0)$ & \\
\hline \multirow[t]{2}{*}{$16-20$} & Positive & $41(93.2)$ & $46(54.8)$ & $<0.001$ \\
\hline & Negative & $3(6.8)$ & $38(45.2)$ & \\
\hline \multirow[t]{2}{*}{$21-25$} & Positive & $54(90.0)$ & $162(63.3)$ & $<0.001$ \\
\hline & Negative & $6(10.0)$ & $94(36.7)$ & \\
\hline \multirow[t]{2}{*}{$26-30$} & Positive & 114 (96.6) & $262(78.9)$ & $<0.001$ \\
\hline & Negative & $4(3.4)$ & $70(21.1)$ & \\
\hline \multirow[t]{2}{*}{$31-35$} & Positive & $133(99.3)$ & $307(86.5)$ & $<0.001$ \\
\hline & Negative & $1(0.7)$ & $48(13.5)$ & \\
\hline \multirow[t]{2}{*}{$36-40$} & Positive & 215 (99.1) & $229(89.8)$ & $<0.001$ \\
\hline & Negative & $2(0.9)$ & $26(10.2)$ & \\
\hline \multirow[t]{2}{*}{$41-60$} & Positive & $1287(99.8)$ & $1088(94.3)$ & $<0.001$ \\
\hline & Negative & $2(0.2)$ & $66(5.7)$ & \\
\hline \multirow[t]{2}{*}{$\geq 61$} & Positive & $278(100)$ & $576(99.5)$ & 0.555 \\
\hline & Negative & $0(0)$ & $3(0.5)$ & \\
\hline \multirow[t]{2}{*}{ Total } & Positive & 2155 (98.7) & 2670 (88.6) & $<0.001$ \\
\hline & Negative & $29(1.3)$ & 345 (11.4) & \\
\hline
\end{tabular}

Data are expressed as number (percent). Abbreviations: HCMV Human cytomegalovirus, IgG immunoglobulin G, N/A not available, SOT solid organ transplantation 
25 (90.0\% vs. $63.3 \% p<0.001), 26$ to 30 (96.6\% vs. $78.9 \%$, $p<0.001$ ), 31 to 35 (99.3\% vs. $86.5 \%, p<0.001$ ), 36 to 40 (99.1\% vs. $89.8 \%, p<0.001)$ and 41 to 60 years of age (99.8\% vs. $94.3 \%, p<0.001)$. The very low HCMV seropositive rates in both SOT recipients $(0 \%)$ and healthy transplant donors $(0.5 \%)$ among those aged $\geq 61$ years were not significantly different $(p=0.555)$ (Table 1$)$.

\section{Anti-HCMV IgG titres in SOT recipients and healthy transplant donors}

The overall HCMV IgG titre in subjects showing HCMV seropositivity was significantly higher among SOT recipients $(n=2155)$ than among healthy transplant donors $(n=2670 ; 64.7 \pm 44.3$ vs. $49.8 \pm 20.6 \mathrm{aU} / \mathrm{mL} ; p<0.001)$. In an analysis according to age distribution, SOT recipients had significantly higher HCMV IgG titres at all analysable ages than the healthy transplant donors (Table 2). ANOVA testing revealed that age subgroups had significantly different HCMV IgG titres in both SOT recipients and healthy donors (overall $p<0.001$ ).

\section{HCMV seroprevalence and titres according to transplant organs}

The kidney $(n=1436,65.8 \%)$ was most common transplant organ in this cohort. Liver transplant (LT, $n=579$ ) and lung transplant (LTx, $n=69$ ) recipients had significantly higher mean ages, compared to kidney transplant $(\mathrm{KT})$ and heart transplant $(\mathrm{HT})(n=100)$ recipients $(p<$ 0.001). In all age groups, overall anti-HCMV IgG titres among LT $(80.1 \pm 54.5 \mathrm{aU} / \mathrm{mL})$ and LTx $(84.3 \pm 68.3 \mathrm{aU} /$ $\mathrm{mL})$ recipients were significantly higher than those among $\mathrm{KT}(59.4 \pm 36.1 \mathrm{aU} / \mathrm{mL})$ and HT $(58.1 \pm 46.9 \mathrm{aU} / \mathrm{mL}) \mathrm{re}-$ cipients $(p<0.001)$. In addition, seropositive rates in all age groups were significantly higher in LT (99.7\%) and LTx (100\%) recipients than in KT (98.3\%) and HT (97.0\%) recipients $(p=0.024)$. However, the HCMV IgG positive rates and titres were similar among the four-transplant organs in SOT recipients aged $\leq 40$ years (Table 3 )

\section{Regression analyses for the effect of age and sex on HCMV seropositivity}

Older age (reference $\leq 40$ years; $41-60$ years: OR, 76.42, 95\% CI, 24.45-238.85, $p<0.001$ and $\geq 61$ years: OR, 4.44, 95\% CI, 1.32-14.91, $p<0.001$ ) was an independent factor associated with a higher HCMV IgG positive rate. Healthy subjects were independently associated with a lower HCMV seropositive rate (OR: 0.12, 95\% CI: 0.08-0.17, $p<0.001$; Table 4).

\section{Discussion}

This study reports a very high HCMV seroprevalence in Seoul, South Korea, a developed country with a high socioeconomic status and well-organised public health system $[20,22]$. As a result, our data may suggest high proportions of both seropositive donors and recipients $(\mathrm{D}+/ \mathrm{R}+)$, which is considered an usual intermediate risk for post-transplant HCMV infection and/or disease via the reactivation of a latent virus $[9,16,23]$. Our overall HCMV IgG seropositive rate is higher than the upper seroprevalence value $(88 \%)$ of the $95 \%$ uncertainty interval in the worldwide general population, based on a recent meta-regression-based estimation [14]. Seronegative individuals were extremely rare among those aged $\geq 31$ years in the SOT recipients. In addition, HCMV seropositive rates and titres were generally proportional to age, except for teenagers. As HCMV may be horizontally transmitted by intimate contact, mainly by hand contact, the lowest seroprevalence observed in subjects between 11 to 15 years of age could be attributed to primary acquisition of HCMV at adolescence owing to improved hygiene [24, 25].

These analyses also revealed high HCMV IgG titres in the elderly population among SOT recipients and healthy subjects. A high HCMV IgG titre and persistent immune reactivation caused by an inflation in the population of long-lived, non-classical HCMV-specific effector memory CD8+ T lymphocytes have been associated with chronic

Table 2 Anti-HCMV lgG titre between solid organ transplant recipients and healthy transplant donors showing HCMV seropositivity by age distribution

\begin{tabular}{|c|c|c|c|}
\hline \multirow{2}{*}{$\begin{array}{l}\text { Age } \\
\text { (years) }\end{array}$} & \multicolumn{2}{|c|}{ Anti-HCMV lgG titre (aU/mL) } & \multirow{2}{*}{$\begin{array}{l}p \text { - } \\
\text { value }\end{array}$} \\
\hline & SOT recipients $(n=2155)$ & Healthy transplant donors $(n=2670)$ & \\
\hline $16-20$ & $56.9 \pm 35.6$ & $37.6 \pm 12.9$ & $<0.001$ \\
\hline $21-25$ & $60.1 \pm 43.9$ & $40.6 \pm 26.8$ & $<0.001$ \\
\hline $26-30$ & $55.0 \pm 38.8$ & $42.9 \pm 30.8$ & $<0.001$ \\
\hline $31-35$ & $54.6 \pm 27.8$ & $45.3 \pm 27.6$ & $<0.001$ \\
\hline $36-40$ & $64.7 \pm 37.1$ & $48.6 \pm 29.5$ & $<0.001$ \\
\hline $41-60$ & $67.8 \pm 45.3$ & $52.1 \pm 13.4$ & $<0.001$ \\
\hline$\geq 61$ & $70.4 \pm 52.5$ & $55.4 \pm 30.1$ & $<0.001$ \\
\hline Total & $64.7 \pm 44.3$ & $49.8 \pm 20.6$ & $<0.001$ \\
\hline
\end{tabular}

Data are expressed as mean \pm standard deviation 
Table 3 HCMV seropositive rates and anti-HCMV lgG titre by transplant organs in solid organ transplant recipients

\begin{tabular}{|c|c|c|c|c|c|}
\hline Age (years) & $\begin{array}{l}\text { Kidney } \\
(n=1436)\end{array}$ & $\begin{array}{l}\text { Liver } \\
(n=579)\end{array}$ & $\begin{array}{l}\text { Lung } \\
(n=69)\end{array}$ & $\begin{array}{l}\text { Heart } \\
(n=100)\end{array}$ & $p$-value \\
\hline \multicolumn{6}{|l|}{$\leq 40$} \\
\hline Seropositive & $478(95.2)$ & 57 (98.3) & $15(100)$ & $34(94.4)$ & 0.716 \\
\hline Titre (aU/mL) & $57.7 \pm 36.6$ & $65.3 \pm 42.6$ & $69.5 \pm 44.4$ & $51.1 \pm 27.0$ & 0.184 \\
\hline \multicolumn{6}{|l|}{$41-60$} \\
\hline Seropositive & $801(100)$ & 400 (99.8) & $33(100)$ & 47 (97.9) & 0.073 \\
\hline Titre (aU/mL) & $60.7 \pm 34.6^{*+}$ & $81.3 \pm 55.5^{*}$ & $88.5 \pm 72.3^{\dagger}$ & $66.4 \pm 60.7$ & 0.001 \\
\hline \multicolumn{6}{|l|}{$\geq 61$} \\
\hline Seropositive & $133(100)$ & $120(100)$ & $21(100)$ & $16(100)$ & - \\
\hline Titre (aU/mL) & $59.9 \pm 44.2^{*}$ & $82.9 \pm 56.3^{*}$ & $90.3 \pm 80.5$ & $48.8 \pm 27.4$ & 0.001 \\
\hline \multicolumn{6}{|l|}{ Total } \\
\hline Age, year & $44.9 \pm 12.4^{* \dagger}$ & $52.3 \pm 12.0^{*} \neq$ & $50.2 \pm 13.0^{\dagger \S}$ & $44.3 \pm 17.3^{\ddagger \S}$ & $<0.001$ \\
\hline Seropositive & 1412 (98.3) & $577(99.7)^{a}$ & $69(100.0)^{a}$ & 97 (97.0) & 0.024 \\
\hline Titre $(\mathrm{aU} / \mathrm{mL})$ & $59.4 \pm 36.1^{*+}$ & $80.1 \pm 54.5^{* \neq}$ & $84.3 \pm 68.3^{\dagger \S}$ & $58.1 \pm 46.9^{\ddagger \S}$ & $<0.001$ \\
\hline
\end{tabular}

Data are expressed as number (percent) or mean \pm standard deviation. ${ }^{*+\$ \S} p$-value $<0.05$ between two groups in post-hoc tests by Bonferroni correction after ANOVA. adjusted $p<0.05$ between two groups using post-hoc analyses based on adjusted standardised residuals. Abbreviation: aU, arbitrary unit

inflammatory diseases, including atherosclerosis, stroke, and coronary artery disease [3, 4, 11, 26-28]. Therefore, the findings of high seropositivity and IgG titres in elderly individuals might suggest the need for further evaluation to prevent HCMV reactivation in a specific population, regardless of their immunocompromised status, as this approach could reduce the morbidity and mortality associated with inflammatory vascular diseases.

Despite the international distribution of HCMV, seropositivity rates around the world vary widely from 18 to $100 \%$, according to geographical location, ethnicity, and specific subpopulation features [14, 29-32]. In a recent study by Li et al., stratification of serological profiles by age group revealed a very high IgG positive rate (97\%) even among young individuals (0-14 years), in contrast to our data [17]. A study conducted in the Netherlands, in 2006 to 2007, reported that non-western individuals (76.7\%) had a considerably higher seroprevalence than native Dutch and western individuals (41.5\%) [31]. In general, the very high HCMV seroprevalence observed in South Korea is similar to that reported in the WHO

Table 4 Multivariate logistic regression analyses to evaluate the factors associated with HCMV IgG seropositivity

\begin{tabular}{llll}
\hline Variables & OR & $95 \% \mathrm{Cl}$ & $p$-value \\
\hline Age, years & & & \\
$\leq 40$ & Ref. & Ref. & Ref. \\
$41-60$ & 76.42 & $24.45-238.85$ & $<0.001$ \\
$\geq 61$ & 4.44 & $1.32-14.91$ & 0.016 \\
Sex, male & 1.33 & $0.98-1.64$ & 0.078 \\
Healthy transplant donor & 0.12 & $0.08-0.17$ & $<0.001$ \\
\hline
\end{tabular}

Abbreviations: $\mathrm{Cl}$ confidence interval, $\mathrm{OR}$ odds ratio, Ref reference
Eastern Mediterranean region, rather than in the European region or the Americas [14, 29, 31, 32]. The different breastfeeding rates and HCMV IgM or IgG seropositive rates of women of reproductive age could contribute to the varied seroprevalence of HCMV between countries or regions, because mother-to-infant vertical transmission may have a major impact on global epidemiology of HCMV [14, 33, 34].

In a SOT setting reported in Hungary, living organ donors were found to have an HCMV seroprevalence of $85 \%$ [35]. However, a detailed analysis of the pretransplant HCMV IgG seropositivity rates and titres among SOT recipients according to age groups or transplant organs as well as in contrast to healthy subjects was not fully reported. In our study, SOT recipients had higher HCMV IgG seropositive rates and titres relative to healthy transplant donors. In addition, the healthy individuals were independently associated with significantly lower HCMV IgG seroprevalence in a logistic regression model. Patients who need SOT have higher HCMV seroprevalence and, therefore, exhibit a higher risk for post-transplant complications associated with HCMV than patients who do not need SOT. Therefore, pre-transplant anti-HCMV IgG assessments are clinically significant in predicting the development of posttransplant HCMV infection and/or disease [9, 16]. In addition, the HCMV serostatus can be clinically useful to stratify the risk groups for post-transplant HCMV reactivation and guide precise HCMV preventive strategies $[9,16]$.

It would be informative to reveal that patients who received SOT in the end stage organ disease state have higher HCMV IgG seropositive rates and titres 
compared to heathy individuals. This finding might be associated with asymptomatic intermittent HCMV replication and immune boosting against HCMV in chronic end stage medical diseases as well as polyclonal immune activation through pro-inflammatory cytokine release upon fulminant acute organ failure leading to SOT [36-39].

This retrospective study has several limitations. We were unable to perform further subgroup analyses according to various underlying morbidities and other immunosuppressive conditions, such as HSCT or haematologic malignancies with severe prolonged neutropenia. In addition, the study design did not allow the serial testing of anti-HCMV IgG titres in SOT recipients at the post-transplant period and subsequent evaluation of the dynamic change of HCMV IgG titres with recovery of transplanted organ function. Moreover, HCMV seroprevalence may differ according to study population, city, and region.

Despite these limitations, this study is the first, to our knowledge, to report a difference in the qualitative and quantitative anti-HCMV IgG findings between SOT recipients and healthy individuals according to serial age groups as well as transplanted organs in SOT recipients.

\section{Conclusion}

The overall HCMV seropositive rate in South Korea was as high as $90 \%$ among both SOT recipients and healthy individuals. Furthermore, the SOT recipients had higher HCMV seropositive rates and IgG titres than the healthy donors. Increased age was an independent factor for high HCMV seropositivity. A large-scale multicentre or regional serosurveillance in the general population as well as among immunocompromised patients who harbour high risks of HCMV infection and lifethreatening end-organ diseases could be helpful.

\section{Abbreviations}

aU: Arbitrary unit; CVD: Cardiovascular disease; HCMV: Human cytomegalovirus; HSCT: Haematopoietic stem cell transplantation; HT: Heart transplantation; Ig: Immunoglobulin; KT: Kidney transplantation; LT: Liver transplantation; LTx: Lung transplantation; SOT: Solid organ transplantation

\section{Acknowledgements}

None.

\section{Authors' contributions}

$Y L$ performed the data collection, preparation, statistical analyses, and interpretation of results and wrote the manuscript. DEK, SGY, KHL, and YGS were involved in the review and revision of the original draft. $\mathrm{SHH}$ provided project administration and intellectual comments about data interpretation and revised the manuscript. All authors read and approved the final manuscript.

\section{Funding}

None.

\section{Availability of data and materials}

The datasets used and/or analysed during the current study are available from the corresponding author on reasonable request.

\section{Ethics approval and consent to participate}

The study was approved by the institution review board in Gangnam Severance Hospital, which waived the requirement for informed consent because of retrospective data collection without personally identifiable information (IRB approval No: 3-2018-0139).

\section{Consent for publication}

Not applicable.

\section{Competing interests}

The authors declare that they have no competing interests.

Received: 18 April 2019 Accepted: 30 October 2019

Published online: 08 November 2019

\section{References}

1. Kaminski H, Fishman JA. The cell biology of Cytomegalovirus: implications for transplantation. Am J Transplant Off J Am Soc Transplant Am Soc Transplant Surg. 2016;16(8):2254-69.

2. Dioverti MV, Razonable RR. Cytomegalovirus. Microbiology spectrum. 2016:4:4.

3. Dupont $L$, Reeves MB. Cytomegalovirus latency and reactivation: recent insights into an age old problem. Rev Med Virol. 2016;26(2):75-89.

4. Poole E, Sinclair J. Sleepless latency of human cytomegalovirus. Med Microbiol Immunol. 2015;204(3):421-9.

5. Fuji S, Einsele H, Kapp M. Cytomegalovirus disease in hematopoietic stem cell transplant patients: current and future therapeutic options. Curr Opin Infect Dis. 2017;30(4):372-6.

6. Zedtwitz-Liebenstein K, Diab-Elschahaw M, Frass M. Human Cytomegalovirus infection in Nonimmunocompromised patients: a retrospective analysis and review of the literature. Intervirology. 2016;59(3): 159-62

7. Al-Omari A, Aljamaan F, Alhazzani W, Salih S, Arabi Y. Cytomegalovirus infection in immunocompetent critically ill adults: literature review. Ann Intensive Care. 2016;6(1):110

8. Couzi L, Pitard V, Moreau JF, Merville P, Dechanet-Merville J. Direct and indirect effects of Cytomegalovirus-induced gammadelta $T$ cells after kidney transplantation. Front Immunol. 2015;6:3.

9. Egli A, Humar A, Kumar D. State-of-the-art monitoring of cytomegalovirusspecific cell-mediated immunity after organ transplant: a primer for the clinician. Clinical infectious diseases : an official publication of the Infectious Diseases Society of America. 2012;55(12):1678-89.

10. Hui J, Qu YY, Tang N, Liu YM, Zhong H, Wang LM, Feng Q, Li Z, He F. Association of cytomegalovirus infection with hypertension risk: a metaanalysis. Wien Klin Wochenschr. 2016;128(15-16):586-91.

11. Wang H, Peng G, Bai J, He B, Huang K, Hu X, Liu D. Cytomegalovirus Infection and Relative Risk of Cardiovascular Disease (Ischemic Heart Disease, Stroke, and Cardiovascular Death): A Meta-Analysis of Prospective Studies Up to 2016. J Am Heart Assoc. 2017:6:7.

12. Moss P. 'From immunosenescence to immune modulation': a re-appraisal of the role of cytomegalovirus as major regulator of human immune function. Med Microbiol Immunol. 2019:208(3-4):271-80.

13. Tu W, Rao S. Mechanisms underlying T cell Immunosenescence: aging and Cytomegalovirus infection. Front Microbiol. 2016;7:2111.

14. Zuhair M, Smit GSA, Wallis G, Jabbar F, Smith C, Devleesschauwer B, Griffiths P. Estimation of the worldwide seroprevalence of cytomegalovirus: a systematic review and meta-analysis. Rev Med Virol. 2019:29(3):e2034.

15. Weltevrede M, Eilers R, de Melker HE, van Baarle D. Cytomegalovirus persistence and T-cell immunosenescence in people aged fifty and older: a systematic review. Exp Gerontol. 2016;77:87-95.

16. Kotton CN, Kumar D, Caliendo AM, Huprikar S, Chou S, Danziger-Isakov L, Humar A. The third international consensus guidelines on the Management of Cytomegalovirus in solid-organ transplantation. Transplantation. 2018; 102(6):900-31

17. Li TD, Li JJ, Huang X, Wang H, Guo XY, Ge SX, Zhang J. Baseline antibody level may help predict the risk of active human cytomegalovirus infection in a HCMV seropositive population. European journal of clinical microbiology \& infectious diseases : official publication of the European Society of Clinical Microbiology. 2017;36(5):863-8. 
18. Antona D, Lepoutre A, Fonteneau L, Baudon C, Halftermeyer-Zhou F, Les Y, levy-Bruhl D. Seroprevalence of cytomegalovirus infection in France in 2010. Epidemiol Infect. 2017;145(7):1471-8.

19. Anoh AE, Mossoun A, Akoua-Koffi C, Couacy-Hymann E, Pauly M, Leendertz SA, Kouakou N'goran E, Schubert G, Weiss S, Hofmann J, et al. Seroprevalence of Cytomegalovirus infection among a rural population of cote d'Ivoire. Viral Immunol. 2017;30(1):54-7.

20. Lee I, Kim S, Kang H. Lifestyle Risk Factors and All-Cause and Cardiovascular Disease Mortality: Data from the Korean Longitudinal Study of Aging. Int J Environ Res Public Health. 2019;16:17.

21. Hamprecht K, Bissinger AL, Arellano-Galindo J, Schweinzer K, Jiang X, Gohring K, Mikeler E, Jahn G. Intrafamilial transmission of human cytomegalovirus (HCMV): long-term dynamics of epitope-specific antibody response in context of avidity maturation. Journal of clinical virology : the official publication of the Pan American Society for Clinical Virology. 2014; 60(2):119-26.

22. Hyun KR, Kang S, Lee S. Population aging and healthcare expenditure in Korea. Health Econ. 2016;25(10):1239-51.

23. Torre-Cisneros J, Aguado JM, Caston JJ, Almenar L, Alonso A, Cantisan S, Carratala J, Cervera C, Cordero E, Farinas MC, et al. Management of cytomegalovirus infection in solid organ transplant recipients: SET/GESITRASEIMC/REIPI recommendations. Transplantation reviews (Orlando, Fla). 2016; 30(3):119-43.

24. Stowell JD, Forlin-Passoni D, Radford K, Bate SL, Dollard SC, Bialek SR, Cannon MJ, Schmid DS. Cytomegalovirus survival and transferability and the effectiveness of common hand-washing agents against cytomegalovirus on live human hands. Appl Environ Microbiol. 2014;80(2):455-61.

25. Cannon MJ, Hyde TB, Schmid DS. Review of cytomegalovirus shedding in bodily fluids and relevance to congenital cytomegalovirus infection. Rev Med Virol. 2011;21(4):240-55.

26. Kim J, Kim AR, Shin EC. Cytomegalovirus infection and memory $T$ cell inflation. Immune network. 2015;15(4):186-90.

27. Klenerman P, Oxenius A. T cell responses to cytomegalovirus. Nat Rev Immunol. 2016;16(6):367-77.

28. Blum A, Giladi M, Weinberg M, Kaplan G, Pasternack H, Laniado S, Miller H. High anti-cytomegalovirus (CMV) IgG antibody titer is associated with coronary artery disease and may predict post-coronary balloon angioplasty restenosis. Am J Cardiol. 1998;81(7):866-8.

29. Cannon MJ, Schmid DS, Hyde TB. Review of cytomegalovirus seroprevalence and demographic characteristics associated with infection. Rev Med Virol. 2010;20(4):202-13.

30. Seale H, Maclntyre CR, Gidding HF, Backhouse JL, Dwyer DE, Gilbert L. National serosurvey of cytomegalovirus in Australia. Clinical and vaccine immunology : CVI. 2006;13(11):1181-4.

31. Korndewal MJ, Mollema L, Tcherniaeva I, van der Klis F, Kroes AC, Oudesluys-Murphy AM, Vossen AC, de Melker HE. Cytomegalovirus infection in the Netherlands: seroprevalence, risk factors, and implications. Journal of clinical virology : the official publication of the Pan American Society for Clinical Virology. 2015;63:53-8.

32. Staras SA, Dollard SC, Radford KW, Flanders WD, Pass RF, Cannon MJ. Seroprevalence of cytomegalovirus infection in the United States, 19881994. Clinical infectious diseases : an official publication of the Infectious Diseases Society of America. 2006;43(9):1143-51.

33. Wang C, Dollard SC, Amin MM, Bialek SR. Cytomegalovirus IgM Seroprevalence among women of reproductive age in the United States. PLoS One. 2016;11(3):e0151996.

34. Hamprecht K, Goelz R. Postnatal Cytomegalovirus infection through human Milk in preterm infants: transmission, clinical presentation, and prevention. Clin Perinatol. 2017;44(1):121-30.

35. Varga M, Gorog D, Kari D, Kornyei E, Kis E, Turyne HJ, Jankovics I, Peter A, Toronyi E, Sarvary E, et al. Cytomegalovirus seroprevalence among solid organ donors in Hungary: correlations with age, gender, and blood group. Transplant Proc. 2011;43(4):1233-5.

36. Han SH. Immunological prediction of Cytomegalovirus (CMV) replication risk in solid organ transplantation recipients: approaches for regulating the targeted anti-CMV prevention strategies. Infection \& chemotherapy. 2017; 49(3):161-75.

37. Yang TY, Chuang YF, Chiu YL. T-cell aging in end-stage renal disease: an evolving story with CMV. Med Microbiol Immunol. 2019.
38. Cavalli G, Foppoli M, Cabrini L, Dinarello CA, Tresoldi M, Dagna L. Interleukin-1 receptor blockade rescues myocarditis-associated end-stage heart failure. Front Immunol. 2017;8:131.

39. Sultan M, Ben-Ari Z, Masoud R, Pappo O, Harats D, Kamari Y, Safran M. Interleukin-1alpha and interleukin-1 beta play a central role in the pathogenesis of fulminant hepatic failure in mice. PLoS One. 2017;12(9): e0184084.

\section{Publisher's Note}

Springer Nature remains neutral with regard to jurisdictional claims in published maps and institutional affiliations.
Ready to submit your research? Choose BMC and benefit from:

- fast, convenient online submission

- thorough peer review by experienced researchers in your field

- rapid publication on acceptance

- support for research data, including large and complex data types

- gold Open Access which fosters wider collaboration and increased citations

- maximum visibility for your research: over $100 \mathrm{M}$ website views per year

At BMC, research is always in progress.

Learn more biomedcentral.com/submissions 